\title{
Análise automática da resposta do aluno em ambiente virtual
}

\author{
Vilson J. Leffa \\ Universidade Católica de Pelotas
}

\begin{abstract}
A análise automática da resposta do aluno para questões abertas tem sido muito pouco usada no ensino mediado por computador, não só por restrições teóricas a uma metodologia que às vezes ainda é associada à idéia de instrução programada, mas também por razões práticas, em virtude da sua notória dificuldade de implementação. Este trabalho descreve um sistema de autoria desenvolvido para oferecer ao aluno um ambiente interativo de aprendizagem, desde a análise da resposta até a oferta de estratégias de aprendizagem. 0 desenvolvimento do sistema foi feito com base em três princípios: (1) da tolerância variável, em que respostas mais e menos corretas são aceitas; (2) da segmentação múltipla, que permite buscar dentro da resposta escrita pelo aluno os segmentos mais pertinentes, e (3) do feedback diversificado, por sua vez subdividido em genérico (informando apenas se a resposta do aluno está correta ou não), situado (identificando as necessidades específicas do aluno) e estratégico (sugerindo pistas para a construção do sentido do texto). A testagem do sistema com professores e alunos sugere que a preparação de atividades que usam um sistema de autoria pode contribuir não só para a melhoria do ensino a distância, mas também para o ensino presencial e para a formação do próprio professor.
\end{abstract}

Automatic analysis of student's answers to open questions has been rarely used in computer-mediated teaching, not only for theoretical restrictions to a methodology that is sometimes associated with the idea of programmed instruction, but also for practical reasons, due to its notorious implementational difficulties. This article describes an authoring system that was developed to offer the student an interactive learning environment, including answer analysis and the delivery of learning strategies. The system was developed according to three principles: (1) variable tolerance, in which more and less correct answers are accepted, (2) multiple segmentation, which allows for searching the most relevant elements in the student's written answer, and (3) diversified feedback, itself subdivided into generic feedback (simply tells the students if answer is correct or not), situated feedback (identifies student's specific needs), and strategic feedback (provides hints to help student construct meaning from text). The authoring system was piloted with teachers and students. The main conclusions was that it could contribute not only to improve distance learning but also classroom learning and teacher development. 


\section{As pedras do caminho e o caminho das pedras}

Um dos tantos desafios no ensino a distância mediado por computador é tornar o professor presente, não só dando intencionalidade pedagógica à atividade proposta, mas também, e principalmente, garantindo ao aluno o desempenho assistido necessário para que ele possa realmente ser ajudado a atingir seu nível potencial de competência. Na virtualidade da rede mundial dos computadores e nas atividades propostas para o ensino dos mais diferentes conteúdos, predomina de modo quase absoluto a duplicação da realidade impressa. 0 recurso da interatividade proporcionado pelo computador é muito pouco explorado.

As razões que levam a essa simples transposição do papel para a tela, sem usar os recursos do novo meio, podem ser de ordem técnica e ideológica. De ordem técnica, nota-se que há muita diversidade e pouca convergência, tanto em termos de software como de hardware. Em termos de software, há, por exemplo, muitos problemas de compatibilidade entre sistemas operacionais básicos, que não só são diferentes, mas estão também constantemente mudando. Isso pode desencorajar o desenvolvimento de aplicativos educacionais, de elaboração mais complexa do que uma apostilha ou um livro impresso. Por outro lado, além do maior investimento que exigem em termos de tempo para sua elaboração, esses aplicativos correm o risco de se tornarem logo obsoletos, com uma sobrevida muito menor do que o material impresso em papel. Uma atividade feita para o computador depende de requisitos sobre os quais não se tem qualquer controle, incluindo não só um sistema operacional básico (Windows, Linux, etc.) mas também outros programas necessários para rodar a atividade, como um browser, por exemplo, que, por sua vez, pode depender de outros aplicativos que deverão ser acionados para executar determinadas tarefas (apresentar corretamente certos caracteres, reproduzir um som, mostrar uma animação, etc.).

A necessidade de toda essa integração de diferentes sistemas pode causar problemas de compatibilidade não só de uma máquina para outra, mas também de um ano para outro. Em geral, quanto mais simples for a atividade, quanto mais próxima estiver do papel impresso, maior será sua longevidade; no outro extremo, quanto mais complexa e interessante for a atividade, quanto mais explorar os recursos da 
máquina, afastando-se da bidimensionalidade estática do papel, maior será o risco de se tornar obsoleta. Na medida em que depender do suporte informatizado, extremamente dinâmico e volátil, a atividade elaborada tem de se ajustar a essa dinamicidade mediante constantes atualizações; o computador, ao mesmo tempo em que facilita a atualização constante, ele a exige com uma freqüência muito maior do que no suporte tradicional da página impressa. Achar um ponto de equilíbrio entre um extremo e outro, conseguindo a melhor relação entre o investimento feito e o benefício obtido, é mais um dos desafios no ensino mediado por computador.

Em termos de hardware, os problemas são parecidos, possivelmente ampliados, já que, além da falta de compatibilidade entre máquinas diferentes, pode haver também problemas de funcionamento. Exemplos de falta de compatibilidade podem ocorrer não só entre máquinas de arquitetura diferentes (IBM e Apple, por exemplo), mas também entre máquinas da mesma linha equipadas com recursos diferentes. A possibilidade de configurar um computador de acordo com as preferências, necessidades e até recursos financeiros de cada usuário, apesar da desejável flexibilidade que oferece, pode também criar problemas em termos de compatibilidade; muita coisa pode ser diferente de um computador para outro: a definição do monitor, a velocidade do processador, a capacidade da memória, a existência ou não de determinados periféricos, etc.

Além dos problemas de falta de compatibilidade, temos também os problemas de funcionamento. Um computador é geralmente composto de vários módulos. Um problema de funcionamento em qualquer um desses módulos compromete todo o sistema. Uma queda na conexão, um disquete que não consegue mais ser lido, um mou se defeituoso, etc. torna a execução da atividade planejada imediatamente inviável.

Há também restrições de ordem ideológica, tanto em relação à Educação a Distância (EAD), com prejuízo para o professor, como em relação aos resultados produzidos por uma aprendizagem mediada por computador, com prejuízo para o aluno. Em relação ao professor, a crítica feita é a de que a EAD é mais uma tentativa do poder econômico de baratear o ensino, massificar a educação e substituir o professor pela máquina. Segundo Barreto (1998), o uso do adjetivo "presencial" no texto da LDB, ao lado da expressão "ensino a distância", é uma estratégia discursiva de efeito perverso, na medida em que associa EAD 
ao que é novo e, por contraponto, associa o termo "presencial" ao que é velho e desgastado:

A legitimação do EAD é produzida na/pela adjetivação do ensino: "presencial". E, como o EAD está sempre associado às "novas linguagens", das "novas tecnologias", o ensino presencial, marcado pelo trabalho docente, tende a ser posto como velho, desgastado, caduco, sem valor. A grande novidade é a cunhagem da expressão ("ensino presencial"), marcando a ressignificação do trabalho docente: esvaziamento e desqualificação do que não seja EAD (BARRETO, 1998, p. 188).

A tentativa de substituição do professor por materiais supostamente auto-explicativo, usando a mistificação da tecnologia para a imposição das leis do mercado, é, segundo a mesma autora, uma conseqüência inevitável da adoção de abordagens de EAD.

Este "novo ensino" compreende um jogo de presença/ausência, no qual a distância é o eufemismo para ausência. Ausência do "Iicenciado", com vários sentidos possíveis: portador de habilitação formal ou autorizado ao exercício sem esta habilitação; afastado temporariamente do trabalho; e dispensado/despedido (BARRETO, 1998, p. 188-189).

Em relação ao aluno, a crítica feita é a de que o computador produz resultados basicamente indesejáveis e prejudiciais. Para citar apenas alguns exemplos:

A instrução mediada por computador, supostamente interativa, que não fornece uma interação verdadeira mas apenas uma resposta mecânica ao esforço do aluno [é mais uma causa] da qualidade cada vez mais impessoal da experiência de vida de um número cada vez maior das crianças americanas. (GREENSPAN, 1998, p. 174).

As crianças vivem uma vida muito mais isolada do que antes. ... Elas simplesmente desaparecem em seus quartos e passam todo o tempo na frente desses aparelhos (KELLY, 1999, p. 79).

A professora é o modelo ideal para a criança [...] Ela [ajuda no desenvolvimento] moral, emocional e [...] intelectual [...]. Somente um ser humano, não uma máquina pode modelar esse tipo de aprendizagem essencialmente humano (FEUERSTEIN, 1994, citado por REPO RT, 2003).

O computador e ciberespaço podem embotar a capacidade da criança em separar o humano do inanimado, contribuir para o escapismo e desligamento emocional [...] (TURKLE, citado por REPORT, 2003). 
Minha preocupação é de que estamos expondo os alunos a muitas versões controladas e fabricadas da realidade e não à natureza como ela realmente é (HAYBRON, 1996, p. 8E).

0 ensino mediado por computador sofre, portanto, de restrições técnicas e ideológicas. As restrições técnicas envolvem o hardware, que os críticos preferem chamar de "parafernália", no sentido mais pejo rativo do termo, e o software, que é criticado, entre outros aspectos, pela falta de conteúdo pedagógico, apresentando uma "versão fabricada da realidade". As restrições ideológicas, por sua vez, concentram-se na idéia da substituição do professor pelo computador.

Cada tipo de problema, técnico ou ideológico, requer um tipo diferente de tratamento. O problema técnico é basicamente uma questão de metodologia de trabalho. Preparar uma atividade mediada por computador é muito diferente de preparar um atividade impressa em papel; pela sua complexidade não pode ser realizada individualmente: tem de ser um trabalho coletivo. 0 computador, pela sua conectividade, ao mesmo tempo que facilita o trabalho em equipe, ele o exige.

Quanto ao problema ideológico, temos uma hipérbole; dá-se ao computador uma importância que ele absolutamente não tem. 0 computador é um objeto e não se pode dar a ele a natureza do sujeito, comparando-o ao professor, como se pudesse substituí-lo. 0 computador é um artefato cultural como o livro, o rádio ou a televisão e, por isso, só pode ser comparado a outro artefato cultural.

A tendência em comparar o computador com o professor sugere, por outro lado, que, mesmo sendo um artefato, ele possui recursos que não são encontrados na página impressa. 0 texto na tela do computador pode ser um texto vivo, dinamicamente conectado a outros textos, que podem ser acessados de modo quase instantâneo, oferecendo uma interatividade que não existe no papel. 0 computador é também capaz de processar dados, comparando-os uns com os outros, e tomar decisões em cima dos resultados. Ele pode, por exemplo, comparar algo que o aluno escreveu com algo que ele deveria ter escrito, e sugerir atividades com base nessas comparações. É o que está sendo proposto neste trabalho. 0 que se busca é uma maneira de auxiliar o aluno a construir significado de um texto que está acima de sua competência lingüística, implementando estratégias de desempenho assistido oferecidas ao aluno no momento preciso, e na quantidade desejada. 


\section{Veja a verdade na análise combinatória}

A questão que se propõe aqui é como auxiliar o aluno a construir significado de um texto que está acima de sua competência lingüística. 0 que se procura é implementar estratégias de desempenho assistido a ser oferecido ao aluno no momento em que ele precisa e na quantidade desejada, usando um sistema de interação simulada. No modelo clássico de análise do discurso da sala de aula, (SINCLAIR e COULTHARD, 1975) a interação dá-se sempre numa seqüência de ciclos (exchanges), divididos em três momentos (moves): o professor inicia, o aluno responde e o professor avalia a resposta do aluno. Embora esse tipo de interação iniciada pelo professor tenha sido muito criticada, a literatura da área mostra que ela predomina até hoje na aula do tipo presencial (LOPES, 1998).

Um levantamento das atividades de ensino mediadas por computador mostra que a oferta de oportunidades para o aluno iniciar o turno é ainda inexistente. 0 que existe são tentativas de recriar a estrutura clássica de iniciação, resposta e avaliação, e mesmo assim com baixo grau de flexibilidade. A maioria das atividades encontradas usa testes de múltipla escolha em que o usuário clica em uma das respostas e é informado se acertou ou não. Atividades com perguntas abertas, em que o aluno é livre para elaborar a resposta, são ainda mais raras; quando existem, às vezes nem analisam a resposta, oferecendo apenas um gabarito que 0 aluno consulta para comparar com o que escreveu, exatamente como se faz num livro impresso. Sistemas de auto ria capazes de produzir atividades com análise automática de respostas abertas, quando existem, não só barram qualquer iniciativa do aluno, como ainda tornam o modelo de Sinclair e Coulthard, já rígido por natureza, ainda mais rígido.

Essa rigidez pode ser demonstrada, por exemplo, num sistema de autoria conhecido por Hot Potatoes, criado pelo "Humanities Computing and Media Center" da University of Victoria, no Canadá. A FIG. 1 mostra uma tela típica produzida pelo sistema com um texto em inglês e uma pergunta do tipo aberta para ser respondida pelo aluno. Pressupondo que 0 autor da atividade tenha oferecido no gabarito a resposta "John Carter", só essa será aceita pelo sistema; se o aluno escrever "The sender is John Carter", a resposta será considerada errada. Embora o sistema permita o fornecimento de até cinco opções no gabarito, qualquer palavra ou mesmo uma vírgula não prevista anula a resposta. 0 sistema, além de 
ser exigente com 0 aluno, é também exigente com o autor da atividade, que precisa prever até o último detalhe tudo que o aluno possa escrever.

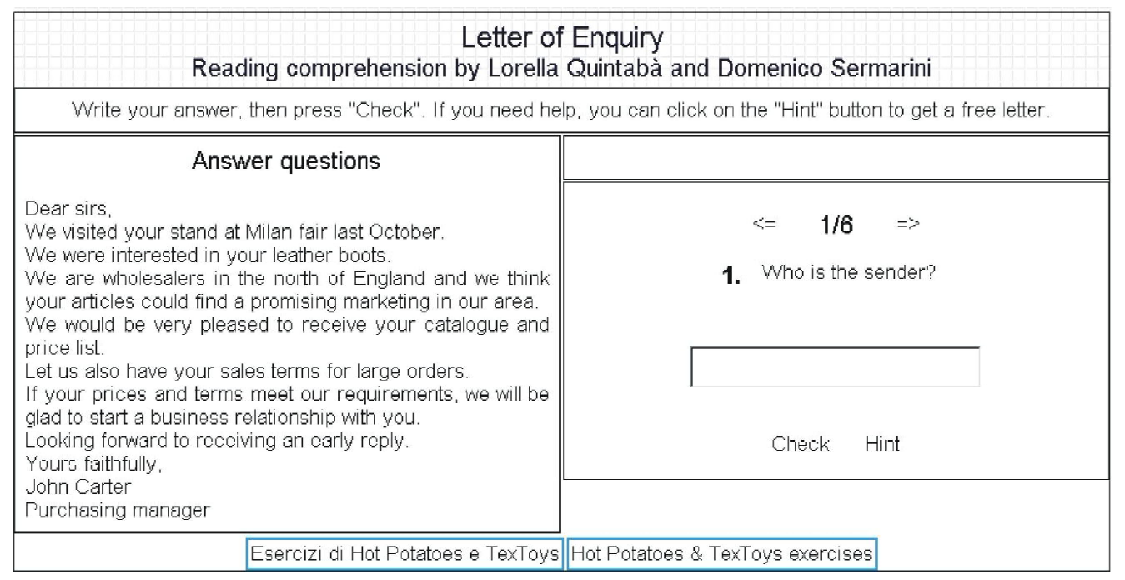

FIGURA 1 - Exemplo de atividade que usa os sistemas de autoria Hot Potatoes (Disponível em <http://digilander.libero.it/Cyberteacher/esercizi/ing_ comm_letterenquiry.htm>. Acesso em: 17 mar. 2002.

O problema, como se percebe, está na análise que é feita da resposta dada pelo aluno. Ou a resposta está totalmente correta ou totalmente incorreta. Não há espaço para graus de correção e o nível de tolerância do sistema é sempre zero. Essa rigidez às vezes leva o sistema a avaliar como erradas respostas que estão corretas, frustrando e desorientando o aluno.

0 que torna o sistema inviável para qualquer pergunta minimamente aberta é o fato de tratar a resposta do aluno como um bloco único, monolítico. Isso pode ser demonstrado através de uma pergunta bem simples. Imaginemos, por exemplo, uma atividade em que 0 aluno tenha de escrever as quatro cores da bandeira brasileira. Como essas cores podem ser escritas em qualquer ordem e como o Hot Potatoes analisa a resposta como um bloco único, 0 autor da atividade terá de oferecer um gabarito com, no mínimo, 24 opções. Isso pode ser demonstrado usando a análise combinatória da Matemática, conforme a fórmula abaixo (Onde se lê que a permutação de 4 é igual ao fatorial de 4 que é igual a $4 \times 3 \times 2 \times 1$, que é igual a 24 permutações):

$$
\mathrm{P} 4=4 !=4 \times 3 \times 2 \times 1=24
$$


Considerando, no entanto, que o aluno pode colocar uma vírgula para separar as três primeiras cores e a conjunção "e" antes da última cor, temos uma resposta com um conjunto de sete elementos, como, por exemplo:

Verde, amarelo, azul e branco

Aplicando a fórmula da Análise Combinatória:

$$
\mathrm{P} 7=7 !=7 \times 6 \times 5 \times 4 \times 3 \times 2 \times 1=5040
$$

elevamos o número de permutações para 5.040. Mais ainda: se 0 autor desejar que o programa seja capaz de avaliar corretamente qualquer resposta certa do aluno - que poderá, por exemplo, escrever "amarela" em vez de "amarelo", ou "branca" em vez de "branco", ou acrescentar palavras como "As cores são..." - o autor, nesse caso, teria de oferecer centenas de milhares de opções, correndo sempre o risco de não prever uma ou outra resposta correta.

0 que se percebe, portanto, é a necessidade de abandonar a idéia de tratar a resposta do aluno como um bloco único - e simplesmente procurar dentro da resposta aqueles elementos que interessam. Se a tarefa for escrever as quatro cores da bandeira brasileira, basta procurar dentro da resposta do aluno cada uma dessas cores, independentemente da ordem em que foram escritas, independentemente de 0 aluno ter ou não usado vírgulas, independentemente de ter ou não usado a conjunção "e". Isso facilita também a vida do autor da atividade; basta que ele forneça para o gabarito, uma única vez, as quatro cores. 0 sistema de autoria deverá estar suficientemente preparado para tomar conta do resto.

Esse foi um dos objetivos do projeto ELO - Ensino de Línguas OnLine - (LEFFA, 2003): criar um sistema de autoria que fosse capaz de dissecar a resposta do aluno, localizar determinados elementos e, com base na análise, não apenas avaliar se a resposta está certa ou errada, mas, usando dados analisados, sugerir estratégias que pudessem levar 0 aluno à resposta correta.

\section{Articule a diversidade}

O funcionamento do sistema proposto e testado dentro do projeto ELO apóia-se em três pontos principais no tratamento da resposta do aluno: (1) o princípio da tolerância variável, (2) o princípio 
da segmentação múltipla e (3) o princípio do feedback diversificado. Todos o princípios, como se nota, estão marcados pelo princípio comum da diversidade.

\section{O princípio da tolerância variável}

Pelo princípio da tolerância variável, a resposta escrita pelo aluno pode ser vista de várias maneiras, desde a tolerância total, na qual não há qualquer restrição a qualquer resposta que o aluno escrever, até a tolerância zero, em que só uma resposta é aceita. Um exemplo de tolerância total pode ocorrer quando se pede a opinião do aluno sobre determinado assunto, em que não se pode avaliar a resposta em termos de certo ou errado; mesmo assim, embora aceitando qualquer coisa que o aluno tenha escrito, ainda é possível fazer algum comentário pertinente. Exemplo:

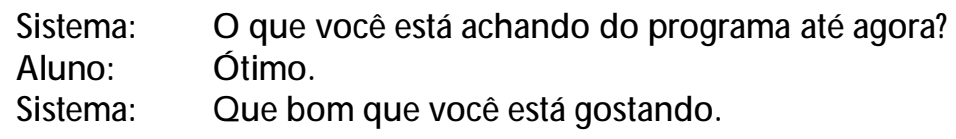

Embora a resposta seja totalmente aberta, existe uma possibilidade razoável de localizar dentro do que o aluno escreveu elementos positivos ou negativos. Esse recurso é de uma simplicidade decepcionante: localizando um elemento positivo ("excelente", "bom", "adorei", etc.) responda "Que bom que você está gostando". Localizando um elemento negativo ("ruim", "péssimo", "horrível", etc.) responda "Vamos tentar melhorar". Não localizando nem um nem outro, faça um comentário neutro, como "Aqui cada um tem o direito de expressar sua opinião".

A tolerância é zero, por outro lado, quando só uma resposta é aceita. Exemplo:

Sistema: Cite o nome da personagem por quem Riobaldo se apaixonou no romance Grande Sertão: Veredas.

Aluno: Diadorim.

Sistema: Certo. Foi Diadorim.

Nesse caso, supondo que 0 autor da atividade tenha fornecido apenas a palavra Diadorim no gabarito, só essa resposta do aluno, e nenhum outra, será aceita.

Entre um extremo e outro, há uma gama de possibilidades em termos de tolerância. Em princípio, quanto maior o número de itens no gabarito, maior a tolerância e vice-versa. 


\section{O princípio da segmentação múltipla}

O funcionamento da tolerância variável está baseado em outro princípio do sistema, que é o da segmentação múltipla, combinado com 0 uso de listas. As listas são segmentos de textos que 0 autor da atividade fornece quando cria o gabarito para analisar a resposta do aluno. Uma lista pode ter um único elemento, vários elementos ou mesmo zero elementos. É essa quantidade variável de elementos, combinada com a extensão também variável de cada segmento (e por isso "segmentação múltipla"), que viabiliza o princípio da tolerância variável.

O elemento de uma lista pode ser qualquer segmento de texto, incluindo uma palavra apenas ("Ceará"), várias palavras ("Rio Grande do Norte"), ou mesmo parte de uma palavra (o prefixo de negação "in"). U ma pergunta do tipo "Conjugue um verbo da língua portuguesa no futuro do pretérito" seria resolvida pelo sistema sem qualquer problema, desde que o autor da atividade fornecesse a lista das respectivas terminações ("ia", "ias", "íamos", "íeis", "iam") - independentemente do verbo que 0 aluno pudesse escolher para conjugar.

Q uando o sistema põe-se em funcionamento, ele percorre cada elemento da lista e vai buscá-lo na resposta do aluno. Imaginemos um exemplo bem simples, no qual o aluno é solicitado a citar uma (e apenas uma) das cores da bandeira brasileira. Para o gabarito, basta uma lista de quatro itens, que, na formulação do sistema de autoria usado aqui, poderia ser representado da seguinte maneira: (verde: amarel: azul: branc). (Note que o uso de parte da palavra, como "amarel" acomoda tanto "amarelo" como "amarela").

Vamos supor que o aluno tenha respondido exatamente 0 seguinte:

\section{Uma cor? OK. Branca!}

O sistema pega o primeiro item da lista do gabarito, que é o segmento "verde", e o procura na resposta do aluno; não o encontrando parte para o item seguinte, "amarel", e, assim, sucessivamente, até chegar ao item "branc", que finalmente é encontrado.

Um ponto fundamental aqui é estabelecer o tipo de relação entre os itens da lista. Os elementos não estão soltos dentro da lista, mas vinculados uns aos outros. Há três possibilidades de vinculação: aditiva, alternativa e adversativa. No modo aditivo, todos os elementos devem 
aparecer na resposta do aluno; há uma vinculação do tipo "e" da lógica booleana (segmento 1 "e" segmento 2 "e" ... segmento n). Exemplo:

Sistema: $\quad$ Cite as cores da bandeira brasileira.

Aluno: $\quad$ Verde, amarelo, azul e branco [Todas devem aparecer na resposta do aluno].

$\mathrm{Na}$ vinculação alternativa, basta que apenas um dos elementos da lista fornecida pelo autor seja citado pelo aluno; a vinculação é do tipo "ou" da lógica booleana. Exemplo:

Sistema: $\quad$ Cite um país da Comunidade Européia.

Aluno: Espanha [Basta citar um país].

ELO aceita também números intermediários de elementos entre 1 e o total da lista. Exemplo:

Sistema: $\quad$ Cite três estados da região Nordeste.

Aluno: $\quad$ Sergipe, Ceará, Rio Grande do Norte [Pelo menos três estados devem ser citados]

Uma lista pode conter não apenas elementos que o aluno pode usar, mas também, opcionalmente, elementos que ele não deve usar. Nesse caso, temos uma vinculação que estamos batizando aqui de "adversativa"; basicamente cria-se uma lista de restrições e a resposta do aluno estará incorreta, se nela aparecer um elemento dessa lista. Exemplo:

Sistema: Qual é a capital da China?

Aluno: Pequim [A reposta será considerada incorreta]

A vinculação adversativa serve principalmente para fornecer um feedback corretivo, apontando especificamente qual é o problema na resposta do aluno. No exemplo acima, a resposta esperada seria "Beijing" e não "Pequim", por exemplo (veja abaixo mais exemplos quando descrevemos o feedback diversificado).

A vinculação dá-se não apenas entre os elementos da mesma lista, mas também entre elementos de listas diferentes. Imaginemos, por exemplo, que o aluno leia um texto propositadamente sem título e seja solicitado a escrever sobre o que é o texto. Supondo que o sintagma nominal "A decadência do capitalismo" fosse uma resposta adequada, poderíamos ter duas listas de elementos, uma para cada substantivo do sintagma (QUADRO 1). Qualquer resposta do aluno que combinasse um elemento da lista 1 com um elemento da lista 2 seria aceita pelo sistema. 
QUADRO 1

Listas de elementos alternativos coordenadas por adição

\begin{tabular}{|c|c|c|}
\hline Lista 1 & & Lista 2 \\
\hline Decadência & & Capitalismo \\
\hline Queda & & Hegemonia americana \\
\hline Fim & & Multinacionais \\
\hline Derrocada & $\&$ & Neoliberalismo \\
\hline Declínio & & Imperialismo \\
\hline
\end{tabular}

0 princípio da segmentação múltipla permite a combinação de diferentes tipos de relação. Note, por exemplo, que os elementos dentro de cada lista do QUADRO 1, estão em vinculação alternativa um com o outro. Já, nesse mesmo exemplo, quando a vinculação se dá entre as duas listas, a ligação é aditiva.

A vinculação entre duas listas pode ser também adversativa. Imaginemos, por exemplo, a seguinte tarefa:

Sistema: Cite três planetas localizados entre a Terra e Plutão.

O sistema, nesse caso, aceitará qualquer resposta do aluno que contenha três das cinco palavras da lista 1 - desde que, na resposta, não apareça qualquer palavra da lista 2 (QUADRO 2).

QUADRO 2

Listas adversativas

\begin{tabular}{lll}
\hline Lista 1 [3] & Lista 2 [*] \\
\hline Marte & Mercúrio \\
Júpiter & \multirow{2}{*}{$\begin{array}{l}\text { Vênus } \\
\text { Saturno }\end{array}$} & Terra \\
Urano & Plutão \\
Netuno & & \\
\hline
\end{tabular}

O princípio da segmentação múltipla, com o uso de listas, tem duas conseqüências imediatas. Em primeiro lugar, aumenta o nível de sofisticação na análise da resposta do aluno, tornando a interação com o sistema, se não mais inteligente, pelo menos mais interativa. Permite respostas abertas sem perder o controle; o sistema é capaz de buscar 
dentro da resposta do aluno não só os elementos que interessam, mas também as relações que interessam. A outra conseqüência imediata é facilitar a elaboração da tarefa por parte do autor da atividade. No caso do texto sobre o capitalismo, por exemplo, bastaria colocar no gabarito a seqüência seguinte, usando a formulação do próprio sistema de autoria:

(decadência : queda : fim : derrocada : declínio) \& (capitalismo : hegemonia americana : multinacionais : neoliberalismo : imperialismo).

Embora isso ainda possa parecer demasiadamente complexo à primeira vista, a formulação é mais simples do que parece. 0 que é inviável em outros sistemas de autoria, já que exigiria milhares de permutações, torna-se pelo menos viável no sistema proposto.

\section{O princípio do feedback diversificado}

O princípio do feedback diversificado completa o ciclo interativo. 0 sistema de autoria permite três tipos de feedback: 0 genérico, 0 situado e o estratégico. 0 feedback genérico é o mais simples: apenas avalia a resposta do aluno e diz se está certa ou errada. É tão universal que pode ser embutido para geração automática em qualquer sistema de autoria: 0 aluno acertou, o sistema escreve "muito bem"; 0 aluno errou, o sistema escreve "tente novamente".

Já o feedback situado é um comentário específico feito em cima de um segmento que aparece na resposta do aluno, simulando, com mais riqueza, o que pode acontecer numa interação face a face. Pode ser do tipo corretivo, quando a resposta está errada, ou repetitivo, quando a resposta está certa, e o feedback retoma alguma coisa do que o aluno escreveu. A seqüência abaixo é um exemplo de feedback situado corretivo:

Sistema: De que trata o texto ao lado?

Aluno: $\quad$ Trata do capitalismo.

Sistema: Realmente o texto fala sobre capitalismo, mas ainda está faltando alguma coisa na sua resposta.

Um dos objetivos do feedback situado, principalmente quando corretivo, é alertar o aluno para alguns aspectos que podem passar despercebidos, às vezes pela freqüência com que são usados, incluindo os erros mais cometidos na aprendizagem de uma língua estrangeira ou fatos da própria língua materna que fazem parte da tradição do ensino 
da língua ("assistir o jogo", "houveram problemas", "Eu vi ele", etc.). A necessidade de alertar 0 aluno para esses aspectos, desenvolvendo o que na literatura da área é conhecido como "noticing" (ELLIS, 1990; SCHMIDT, 1995, SKEHAN, 1998), justifica a inserção desse tipo de feedback na atividade. Exemplos de algumas seqüências simuladas, apoiadas pelo ELO:

Sistema: De acordo com o texto, por que o jogo foi suspenso?

Aluno: $\quad$ Porque houveram problemas de disciplina.

Sistema: Sua resposta está co rreta. Note, porém, que muitos acham que se deve escrever "houve problemas".

Sistema: What does John do?

Aluno: $\quad H e$ is doctor.

Sistema: Use article before 'doctor'.

Além dos tipos genérico e situado de feedback, sentimos também a necessidade de introduzir o feedback estratégico. Enquanto 0 feedback genérico fica na avaliação da resposta, certa ou errada, e o situado mostra a origem do problema, o feedback estratégico tenta sugerir estratégias de aprendizagem que possam levar 0 aluno à resposta certa. Não se dá a resposta ao aluno, mas tenta-se mostrar-lhe como chegar a ela. 0 exemplo abaixo mostra uma simulação em que, depois do feedback situado, sem produzir o resultado desejado, o sistema aciona uma tentativa de feedback estratégico, pedindo que 0 aluno releia o primeiro parágrafo.

Sistema: De que trata o texto ao lado?

Aluno: $\quad$ Trata do capitalismo.

Sistema: Realmente o texto fala sobre capitalismo, mas ainda está faltando al guma coisa na sua resposta.

Aluno: É sobre o capitalismo selvagem.

Sistema: Não é bem isso ainda. Veja o que diz o primeiro parágrafo, pense um pouco e tente novamente.

A principal vantagem do feedback estratégico é que ele pode ser dado ao aluno não só no exato momento em que ele demonstra necessidade de aplicar a estratégia, mas também na quantidade exata: o sistema de autoria proposto aqui permite a oferta de uma sucessão de pistas até que o aluno chegue à resposta desejada. Num último caso, na falha geral de todas as tentativas, a resposta é segmentada e mostrada em partes para 0 aluno. 


\section{Não compare o computador com o professor}

A análise automática da resposta do aluno tem sofrido muitas restrições teóricas, principalmente pelo tratamento alegadamente mecanicista dado à interatividade, que não tem condições de reproduzir a riqueza da interação face a face; não há como dar conta da imprevisibilidade do ato de aprender, e a construção do conhecimento acaba sendo feita de modo unilateral, sem dar oportunidade para a contribuição do aluno. 0 problema nessa linha de argumentação é que, no momento da preparação da atividade, trata-se o computador como se fosse uma página impressa, fazendo uma simples transposição do papel para o ambiente virtual, sem explorar os recursos disponíveis do novo meio. Depois, no momento em que o aluno executa a atividade, compara-se 0 computador com o professor, vendo-se no objeto um substituto para 0 sujeito.

Mostramos neste trabalho como o computador pode substituir a folha de papel, proporcionando uma análise automática da resposta do aluno. Para isso, exploramos a idéia da diversidade em três níveis distintos: (1) permitindo respostas mais e menos corretas, (2) usando um gabarito baseado em listas e (3) fornecendo feedback diversificado. 0 computador não substitui o professor, mas substitui com vantagem a folha de papel.

As conclusões práticas da proposta, junto a professo res e alunos, são ainda preliminares, partindo de minicursos oferecidos para os professores e de algumas aulas que foram observadas. Podem ficar como hipóteses para futuros trabalhos.

0 que se percebeu com os professores que elaboravam as atividades para seus alunos, usando o sistema de autoria, foi a possível contribuição que o sistema pode dar ao ensino presencial. Para ter uma atividade executável, os professo res precisavam concluir uma série de tarefas: (1) encontrar um texto, (2) elaborar perguntas, (3) preparar os diferentes tipos de feedback, incluindo a sugestão de estratégias, (4) pilotar a atividade para ver o que funcionou ou não e, finalmente, (5) editar a atividade para a versão final corrigindo as falhas. Ao longo desse processo, parece ter havido, ao menos para alguns professores, uma aprendizagem de como deve ser uma aula. 0 sistema de autoria, com seus enquadramentos e exigências, parece ter contribuído indiretamente para a formação desses professores. É possível que o 
ensino a distância - considerando a necessidade de preparar o próprio material, individual ou coletivamente - possa contribuir mais para o ensino presencial do que vice-versa.

\section{Referências}

BARRETO, R. G. Ensino a distância: uma tentativa de aproximação. In: CONG RESSO DA ASSEL, 7, Rio de Janeiro. Anais... Rio de Janeiro: ASSELRIO, p. 179-190, 1998.

ELLIS, R. Instructed second language acquisition. Oxford: Basil Blackwell, 1990. $240 \mathrm{p}$.

GREENSPAN, S. I. \& BENDERLY, B. L. The growth of the mind and the endangered origins of intelligence. New York: Harpercollins Publishers, 1998. $364 \mathrm{p}$.

HAY BRO N, R. Too much emphasis on computers. Cleveland Plain Dealer, Aug. 6, 1996, p. 8E.

KATY, K. Get that TV out of your children's bedroom. U.S. Newsand World Report, Nov. 29, 1999, p. 79.

LEFFA, V. J. Ensino de Línguas On-Line (ELO). Disponível em http:// elo.ucpel.tche.br. Também disponível em http://www.leffa.pro.br/elo/ index.html. Acesso em: 17 mar. 2003.

LOPES, H. B. T. 0 discurso do professor: ocupação e paráfrase. Trabalho apresentado no V Congresso Brasileiro de Língüística Aplicada. Porto Alegre: 31 ago.- 4 set. 1998. In: LEFFA, Vilson J. (Compilador). TELA (Textos em Lingüística Aplicada) [CD-ROM]. Pelotas: Educat, 2000.

REPORT. Fool's gold: a critical look at computers in childhood. 2003. Disponível em http://www.allianceforchildhood.net/projects/computers/ computers_reports.htm Acesso em: 18 mar. 2003

SCHMIDT, R. Consciousness and foreign language learning: A tutorial on the role of attention and awareness. In (Ed.). Attention and awareness in foreign language teaching and learning (Technical Report No. 9). Honolulu: University of Hawai at Manoa, 1995.

SINCLAIR, J. McH.; COULTHARD, M. Towardsan analysis of discourse: the English used by teachers and pupils. Oxford: OUP, 1975.

SKEHAN, P. A cognitive approach to language learning. Oxford: Oxford University Press, 1998. 